\title{
Aus der Praxis für die Praxis
}

SR Nexco Flask ist eine neue Küvette, die das Überpressen von Gerüststrukturen mit lichthärtenden Verblendkompositen ermöglicht. Der entscheidende Vorteil der neuen Küvette: Mit ihr können insbesondere große, weitspannige Restaurationen effektiv und schnell verblendet werden.

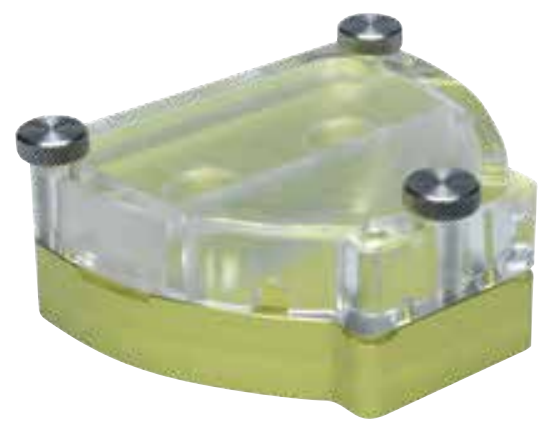

Die Küvette verfügt über griffige, große Befestigungsschrauben. Diese sind nicht, wie größtenteils üblich, fest vorinstalliert, sondern lassen sich ohne Führungsstifte flexibel einfügen, was die Handhabung verbessert. Der Küvettendeckel ist transparent und damit lichtdurchlässig. Er ermöglicht die Lichtpolymerisation von allen Seiten und sorgt so für die gleichmässige Aushärtung des lichthärtenden Verblendkomposits. Neben einer zusätzlichen Bodenplatte zur Anpassung der Höhe je nach Restauration gehört auch ein separates Block-Out für kleinere Restaurationen zur Ausstattung. Dieses ermöglicht es, den Materialverbrauch auf das erforderliche Minimum zu reduzieren. Positionierungszapfen verhindern ein Wegrutschen des Deckels. Einkerbungen an den Seiten erleichtern die Trennung von Ober- und Unterteil, während die seitlichen Öffnungen optimal auf die Mischkanülen des Klarsilikons Transil $F$ zugeschnitten sind. Dies erleichtert die Handhabung des Silikons und macht dieses ideal zur Verwendung mit SR Nexco Flask. Zudem sorgt das gute Fliessverhalten von Transil F für ein einfaches Ummanteln des eingebetteten Gerüsts. Die neue Küvette erweitert das bestehende SR Nexco-Produktsystem und ist ideal auf die SR NexcoMassen abgestimmt.

Nach einer Pressemitteilung der Ivoclar Vivadent GmbH, Ellwangen, Jagst

Internet: www.ivoclarvivadent.de 